\title{
EXPERIÊNCIAS DE LEITORES COM O USO DO PODCAST ${ }^{1}$ EXPERIENCES OF READERS WITH THE USE OF PODCAST
}

\author{
Francisca Alves de Medeiros Couto² \\ Marcos Nonato de Oliveira ${ }^{3}$
}

RESUMO: Refletindo sobre experiências e crenças no ensino e aprendizagem, metodologias ativas e tecnologias digitais, este artigo investiga crenças e experiências construídas durante uma intervenção em sala de aula: projeto "Leitores que formam leitores". Trata-se de uma investigação qualitativa e interpretativista, sustentada pela etnometodologia. Os participantes são oito alunos do 9o ano, o instrumento utilizado foi relato de experiências. Os resultados revelam crenças de que o projeto foi trabalhoso, porém produtivo; que promoveu experiências, pesquisas e produção (resenhas, blogs, podcasts) e resultados significativos. Reconhecemos que o estudo das experiências e crenças é considerado relevante para a compreensão dos processos que acontecem dentro da sala de aula. (MICCOLI, 2007). As dificuldades foram relacionadas ao trabalho colaborarativo. Estudos sobre experiências e crenças podem auxiliar na qualidade da educação. Vale destacar que considerar as crenças que alunos constroem a partir das experiências é fundamental para pensarmos em transformações nas práticas docentes (BARCELOS, 2004).

PALAVRAS-CHAVE: Experiências. Crenças. Tecnologias digitais. Aprendizagem baseada emprojetos.

ABSTRACT: Reflecting on experiences and beliefs in teaching and learning, active methodologies and digital technologies, this article investigates beliefs and experiences built during an intervention in the classroom: "Readers who train readers" project. It is a qualitative and interpretative investigation, supported by ethnomethodology. The participants are eight 9th grade students, the instrument used was an experience report. The results reveal beliefs that the project was laborious, but productive; which promoted experiences, research and production (reviews, blogs, podcasts), and positive results. We recognize that the study of experiences and beliefs is considered relevant for understanding the processes that take place within the classroom. (MICCOLI, 2007). The

\footnotetext{
${ }^{1}$ Artigo recebido em 14/02/2020 e aceito para publicação em 20/06/2020.

${ }^{2}$ Mestranda pela UERN; Especialista em Tecnologias em Educação pela PUC/RIO; Professora de Língua Portuguesa da Educação Básica/CE. ORCID: https://orcid.org/0000-0002-6064-1534. E-mail: edilaniajati@gmail.com.

${ }^{3}$ Doutor pela Universidade Federal do Rio Grande do Norte/UFRN e professor da Universidade do Estado do Rio Grande do Norte/UERN. ORCID: https://orcid.org/0000-0002-4888-2933. E-mail marcosnonato@uern.br.
} 
difficulties were related to collaborative work. Studies on experiences and beliefs can assist in the quality of education. It is worth mentioning that considering the beliefs that students build from their experiences is fundamental for thinking on changes in teaching practices (BARCELOS, 2004).

KEYWORDS: Experiences. Beliefs. Digital technologies. Project-based learning.

No âmbito da educação, há sempre que se repensar os processos de organização do tempo, do espaço, do currículo e das metodologias. Investimentos são feitos, principalmente na implantação das tecnologias telemáticas de alta velocidade, que visam conectar docentes, discentes e administradores (MORAN, 2013). No contexto do ensino de língua portuguesa, devemos considerar que "[...] das novas tecnologias nascem novos desafios advindos das novas formas de produção, pois estas determinam novas formas de organização do discurso, novos gêneros e novas formas de ler e escrever" (GOULART p. 53, 2007). É necessário, desse modo, redimensionar o fazer pedagógico. Nesse sentido, a aprendizagem baseada em projetos aliada ao uso das tecnologias digitais, de acordo com José Manuel Moran (2018), pode originar diversas possibilidades de inovação pedagógica e consequentemente de melhorias na aprendizagem dos alunos.

Outrossim, refletir sobre as experiências e crenças de alunos e professores no contexto escolar é importante para conhecermos os aspectos que permeiam os processos de ensino e aprendizagem. De acordo com Ana Maria Ferreira Barcelos (2006, p. 18), o conceito de crenças está relacionado à compreensão que o indivíduo faz da realidade, uma maneira de pensar, ver e perceber o mundo e seus fenômenos. A referida pesquisadora acrescenta que as crenças são "co-construídas em nossas experiências e resultantes de um processo interativo de interpretação e (re) significação". Assim, as experiências influenciam as crenças e estas motivam as ações que o indivíduo realiza em seu cotidiano. São, portanto, aspectos que devem ser considerados visando a melhoria dos resultados educacionais.

O presente artigo tem como objetivo investigar as experiências e as crenças dos alunos do ensino fundamental construídas a partir da aplicação de uma intervenção em sala de aula: o projeto "Leitores que formam leitores". As ações da referida inter-

Interdisciplinar, Săo Cristóvầo, UFS, v. 33, jan-jun, p. 84-100, 2020 D0l: https://doi.org/10.47250/intrell.v33il.14179 
venção contemplaram o uso de tecnologias digitais, em especial o podcast, e a aprendizagem baseada em projetos com o propósito de incentivar a leitura nas aulas de língua portuguesa. Nessa perspectiva, apresentamos discursões estabelecidas a partir das crenças dos alunos formadores sobre as experiências vivenciadas a partir do referido projeto. Acreditamos que essas tecnologias podem contribuir para novas práticas de leitura, haja vista a influência que as redes de comunicação e os diferentes aplicativos possibilitam aos usuários. No ensino de língua portuguesa, explorar esses recursos digitais, através dos múltiplos contextos virtuais de aprendizagem, significa proporcionar o desenvolvimento do ensino da leitura.

\section{Experiências e crenças no ensino e aprendizagem}

O estudo das experiências e crenças é considerado relevante para a compreensão dos processos que acontecem dentro da sala de aula. (MICCOLI, 2007; BARCELOS, 2004). Laura Stella Miccoli (2007) enfatiza que, diferente do objetivo tradicional onde se busca a verdade através da relação de causa e efeito, a pesquisa com foco na experiência busca um significado aprazível para uma comunidade em um determinado momento. Isso vai ao encontro dos estudos em Linguística Aplicada no que se refere ao ensino de línguas, pois o foco são as experiências de alunos e professores em sala de aula.

Para Barcelos (2004), as crenças são concebidas como conhecimentos que são construídos para dar suporte às ações humanas e que são passíveis de reconstruções. A autora acrescenta que considerar as crenças que alunos constroem a partir das experiências é fundamental para haver transformações nas práticas docentes. Esse tipo de investigação deve envolver: "(a) as experiências e ações desses alunos; (b) suas interpretações dessas experiências; (c) o contexto social e como ele molda as experiências dos alunos, e (d) como os alunos usam suas crenças para lidar com a tarefa complexa de aprender línguas". (BARCELOS, 2004, p. 148). Logo, os estudantes devem ser considerados como seres reflexivos que constroem crenças a partir de suas experiências.

Por essa ótica, as crenças são ideias ou concepções construídas a partir das experiências vividas, num contexto interativo, 
podendo ser reconstruídas ou ressignificadas ao longo do tempo. Assim, as crenças são passíveis de mudança e dependem do contexto social e cultural. São também individuais, haja vista cada indivíduo ser capaz de construir suas próprias crenças. $\mathrm{E}$, em virtude de seu caráter dinâmico de configuração e reconfiguração constantes, as crenças são paradoxais. A complexidade do estudo das crenças no contexto educacional se dá, conforme Barcelos (2007), em razão de variadas crenças de diferentes naturezas guiarem as ações tanto de alunos como de professores. A referida autora salienta que é primordial alunos e professores refletirem e discutirem sobre suas crenças para que possam pensar e agir de forma cada vez mais crítica e reflexiva sobre os processos de ensinar e aprender. Na visão de Oliveira e Lima (2016, p. 13), “a leitura estabelece uma ligação entre o leitor e o mundo, favorecendo a reflexão, esclarecendo dúvidas e evidenciando fatores que estão despercebidos". Nesse contexto, emerge uma crença de leitura que considera todos os modos semióticos.

Através desses pressupostos, entendemos que a compreensão das experiências e crenças como construto teórico pode ser substancial para alicerçar novos olhares sobre os processos de ensino e de aprendizagem em sala de aula (BARCELOS, 2004; MICCOLI, 2007). No tocante ao ensino de leitura, Oliveira e LIMA (2016, p.112) afirmam que "a leitura deve ser considerada como um processo que envolve atividades com textos de diversas naturezas, em situações cotidianas de comunicação". Os autores mostram que a leitura pode e deve conduzir a repensar as mensagens que são publicadas no cotidiano. Trata-se de ampliar a percepção sobre esses processos, trazendo possíveis respostas para questões que envolvem o papel do professor, os métodos de ensino utilizados, como também os tipos de aprendizagem dos alunos.

\section{A aprendizagem baseada em projetos, tecnologias digitais e leitura}

O estudo sobre o uso de metodologias ativas na educação não é recente, tendo em vista que grandes estudiosos da área têm apontado a aprendizagem ativa como caminho para o desenvolvimento mais efetivo de competências e habilidades na área educacional. John Dewey (1979), Freire (2005), Fernando Hernández (1998b), entre muitos outros e em diferentes épocas, 
acreditam que os aprendizes se envolvem de forma ativa no processo de aprendizagem quando partem daquilo que é significativo para eles, dentro de seus níveis de competências e atuando de forma ativa no processo. Esses autores entendem que a sala de aula tradicional, onde o professor simplesmente transmite os conteúdos, não condiz com uma aprendizagem mais profunda, que "requer espaços de prática frequentes (aprender fazendo) e de ambientes ricos em oportunidades. Tais metodologias colocam os estudantes como principais responsáveis por suas aprendizagens, criando oportunidades para que eles desenvolvam a criticidade e a reflexão através de atividades conduzidas e incentivadas pelo professor. As metodologias ativas, de acordo com Moran (2018, p. 2), "são estratégias de ensino centradas na participação efetiva dos estudantes na construção do processo de aprendizagem, de forma flexível, interligada, híbrida".

Ainda apoiados em Moran (2018, p. 695), uma metodologia ativa que trabalha o pensamento crítico e criativo e o entendimento de que há muitas possibilidades de realizar uma atividade é a aprendizagem baseada em projetos. Nessa modalidade, os alunos podem desenvolver o pensamento questionador, crítico e criativo, buscando soluções possíveis para questões ligadas a sua vida, dentro ou fora do contexto escolar. Essa perspectiva de ensino "adota o princípio da aprendizagem colaborativa, baseada no trabalho coletivo. Buscam-se problemas extraídos da realidade a partir da observação realizada pelos alunos dentro de uma comunidade". (MORAN, 2018, p. 727). Por esse viés, a aprendizagem baseada em projetos pode se constituir numa abordagem importante para o trabalho de incentivo à formação de leitores nas aulas de língua portuguesa, uma vez que abre espaços de reflexão, pesquisa e resolução de problemas que podem estar relacionados à redução do percentual de alunos não leitores.

Em relação a aprendizagem baseada em projetos aliada ao uso de tecnologias, Maria Elizabeth Bianconcini de Almeida e José Armando Valente (2012, p. 67) afirmam que, para um funcionamento real e significativo, são necessários dois elementos: "que as atividades e os projetos que o aluno desenvolve sejam relacionados com a sua realidade; e que, além de disponibilizar os diferentes meios tecnológicos, o professor entenda as especificidades desses meios e saiba usá-los como recursos pedagógicos". 
Sobre o primeiro elemento, quando se envolve os estudantes em atividades que refletem seu contexto e seus interesses, faz-se emergir discussões significativas e, como afirma Henández (1998), proporcionam a formação de cidadãos com autonomia. Fica evidente que, em um período de tantas transformações e incertezas, é importante trabalharmos com metodologias mais flexíveis, com projetos reais buscando transformar nossas práticas de ensino transmissivo em contextos de aprendizagem mais dinâmicos e realmente relevantes para nossos alunos.

O processo de formação de leitores requer uma reflexão sobre os aspectos que envolvem o incentivo à leitura, ou seja, a forma como esse processo acontece pode ou não contribuir para a formação de leitores. Nesse sentido, Regina Zilberman (2013, p. 221) afirma que quando a escola cumpre seu papel, no contexto da formação de leitores "transforma o indivíduo habilitado à leitura em um leitor". Do contrário, se a escola falha nesse propósito, pode afastar o aluno de todo tipo de leitura. Buscando compreender como despertar esse interesse, lançamos nosso olhar para a mediação da leitura, na perspectiva da dialogicidade, um dos eixos fundantes das teorias freirianas, que pode ser entendida como prática fundamental para construção e/ou apropriação do conhecimento. Sendo o diálogo a essência da educação, é através dele que nascem as práticas sociais e culturais numa ação autônoma e libertadora, nas quais todos precisam ser reconhecidos e valorizados. Portanto, de acordo com Paulo Freire (2011, p. 91), “o diálogo é este encontro dos homens, mediatizados pelo mundo, para pronunciá-lo, não se esgotando, portanto, na relação eu-tu". Desse modo, o desejo de ler e de conhecer nasce quando o interesse em aprender ou descobrir é despertado, numa relação horizontal, dialógica e dialética entre professor e aluno.

Sobre a prática de leitura em meio digital, Magda Soares (2004) afirma que, por vivermos um momento de transformações nos processos de leitura e escrita decorrentes da presença cada vez maior das tecnologias de comunicação eletrônica, torna-se oportuno verificar se o estado ou condição das práticas de leitura e escrita digitais (letramento na cultura digital) são diferentes das práticas tradicionais (letramento na cultura do papel). Sobre isso, Valéria Ribeiro de Castro Zacharias (2016, p. 21) ressalta que o letramento digital "[...] exige tanto a apropriação das tecnologias -

Interdisciplinar, Săo Cristóvầ, UFS, v. 33, jan-jun, p. 84-100, 2020 D0I: https://doi.org/10.47250/intrell.v33i1.14179 
como usar o mouse, o teclado, a barra de rolagem, ligar e desligar os dispositivos - quanto o desenvolvimento de habilidades para produzir associações e compreensões nos espaços multimidiáticos". Em outras palavras, de acordo com Carla Viana Coscarelli e Ana Elisa Ribeiro (2014, p. 5), "letramento digital diz respeito às práticas sociais de leitura e produção de textos em ambientes digitais". O letramento digital, a partir dessa conceituação, refere-se à capacidade de realizar ações, em meio digital, de forma satisfatória, demandando habilidades de leitura mais específicas, levando-se em conta que os textos apresentam características como hipertextualidade, multimodalidade e interatividade.

Nosso artigo traz os resultados da aplicação de uma intervenção em uma sala de aula de língua portuguesa, por meio de um projeto denominado "Leitores que formam leitores". Assim, iniciamos a intervenção partindo do objetivo geral de incentivar e potencializar as práticas de leitura, nas aulas de língua portuguesa, usando as tecnologias digitais, em especial, o podcast. O projeto foi dividido em duas fases: a primeira envolveu a produção dos podcasts (áudios de resenhas incentivando o interlocutor a ler a obra sugerida). Nos programas de produção de podcasts, foram gravadas as resenhas dos livros de ficção preferidos dos alunos formadores, a partir de seus próprios repertórios de leitura. Os podcasts e os links de acesso aos livros foram publicados em um blog na internet. Todo o processo de produção foi realizado por um grupo de alunos voluntários que assumiram como objetivo incentivar a formação de novos leitores na sala de aula. Assim, foram chamados de "formadores". O referido grupo foi constituído por alunos que se autoindicaram como leitores ativos. Esses estudantes conduziram, sob a nossa orientação, os procedimentos de pesquisa e produção de podcasts (Quadro 1).

A segunda fase envolveu todos os alunos do 9 ano. O material produzido na primeira fase foi exposto pelos alunos formadores e os demais estudantes foram convidados a "navegar" no blog e acessar os podcasts. Daí, então, poderiam escolher um dos textos indicados e realizar sua leitura. O corpus constituiu-se dos relatos de experiência produzidos pelos alunos formadores (ALF), contendo suas percepções sobre o projeto. Para a análise foram selecionados cinco relatos dentre os oito que foram produzidos pelos participantes da primeira fase. 
Quadro 1 - Primeira fase do Projeto LFL

PRODUÇÃO DE PODCASTS (ALUNOS FORMADORES ENVOLVIDOS NO PROCESSO DE PESQUISA E PRODUÇÃO)

\begin{tabular}{|c|c|c|}
\hline AÇÕES & LOCAL E C/H & DESCRIÇÃO \\
\hline $\begin{array}{l}1 \text { Sensibiliza- } \\
\text { ção }\end{array}$ & $\begin{array}{l}\text { Sala de aula - } \\
1 \mathrm{~h} / \mathrm{a}\end{array}$ & $\begin{array}{l}\text { Emissão da animação Os fantásticos livros } \\
\text { voadores do Senhor Lessmore; conversa } \\
\text { sobre a importância da leitura e o uso das } \\
\text { tecnologias. }\end{array}$ \\
\hline $\begin{array}{l}2 \text { Constituição } \\
\text { da equipe de } \\
\text { formadores }\end{array}$ & $\begin{array}{l}\text { Sala de aula - } \\
1 \mathrm{~h} / \mathrm{a}\end{array}$ & $\begin{array}{l}\text { Formação do grupo de alunos leitores } \\
\text { para conduzirem os procedimentos de } \\
\text { estudo, pesquisa e produção de podcasts. }\end{array}$ \\
\hline $\begin{array}{l}3 \text { Pesquisas e } \\
\text { organização } \\
\text { do cronogra- } \\
\text { ma }\end{array}$ & $\begin{array}{l}\text { Centro de mul- } \\
\text { timeios - } 2 \mathrm{~h} / \mathrm{a}\end{array}$ & $\begin{array}{l}\text { Pesquisas e organização dos temas e do } \\
\text { cronograma para realização de oficinas. } \\
\text { Início dos estudos sobre a criação de pod- } \\
\text { casts. Uso tutoriais, vídeos e textos. }\end{array}$ \\
\hline $\begin{array}{l}4 \text { Oficina I: Gê- } \\
\text { nero resenha. }\end{array}$ & $\begin{array}{l}\text { Laboratório de } \\
\text { Informática - } 2 \\
\text { h/a }\end{array}$ & $\begin{array}{l}\text { Estudo do gênero resenha. Início da pro- } \\
\text { dução da resenha da obra escolhida. }\end{array}$ \\
\hline $\begin{array}{l}5 \text { Oficina II: O } \\
\text { Audacity e o } \\
\text { Soundcloud }\end{array}$ & $\begin{array}{l}\text { Laboratório de } \\
\text { Informática - } 2 \\
\text { h/a }\end{array}$ & $\begin{array}{l}\text { Contato inicial com o programa Audacity } \\
\text { (gravador e editor de áudios) e do Soun- } \\
\text { dcloud (plataforma on-line de publicação } \\
\text { de áudios/podcasts). }\end{array}$ \\
\hline $\begin{array}{l}6 \text { Oficina III: } \\
\text { Produzindo } \\
\text { podcasts. }\end{array}$ & $\begin{array}{l}\text { Laboratório } \\
\text { Informática - } 2 \\
\text { h/a }\end{array}$ & $\begin{array}{l}\text { Produção dos primeiros áudios usando o } \\
\text { Audacity. }\end{array}$ \\
\hline $\begin{array}{l}7 \text { Oficina IV: } \\
\text { Criando blogs }\end{array}$ & $\begin{array}{l}\text { Laboratório de } \\
\text { Informática - } 2 \\
\text { h/a }\end{array}$ & $\begin{array}{l}\text { Criação do blog para publicação dos } \\
\text { podcasts. }\end{array}$ \\
\hline 8 Reuniões & $\begin{array}{l}\text { Laboratório de } \\
\text { Informática - } 6 \\
\text { h/a }\end{array}$ & Edição e organização do blog. \\
\hline
\end{tabular}

Fonte: Autoria própria.

\section{As experiências dos formadores de leitores}

Os métodos utilizados nos processos de ensino e aprendizagem nas escolas são essenciais para a qualidade da educação. Mas o que os estudantes pensam acerca das formas de aprender? A visão dos estudantes, em concordância com Miccoli (2014), é fundamental para se refleti $r$ sobre vários aspectos do processo de ensino e aprendizagem. Para a referida autora, a experiência é um processo que, ao ser narrado, deixa de ser um acontecimento 
isolado e oferece oportunidade de se "ampliar o sentido dessa experiência e de definir ações para mudar e transformar seu sentido original bem como aquele que o vivenciou". Embasados nisso, apresentamos discussões sobre como os alunos formadores perceberam o processo de desenvolvimento do projeto "Leitores que formam leitores" e que crenças foram construídas a partir dessas experiências. Dessa forma, procuramos identificar, nos relatos, as percepções relativas ao processo metodológico adotado, às aprendizagens construídas, aos resultados e/ou expectativas e às dificuldades encontradas. Os fragmentos, a seguir, versam sobre processo o metodológico utilizado.

ALF1: Deu trabalho, [...] mas foi bem proveitoso também porque essa experiência mostra que é possível que simples alunos como nós, do interior, possam criar uma coisa bem inovadora e realmente interessante para nossa própria comunidade.

ALF3: Participar desse projeto foi muito bom. Tudo começou porque a professora queria que a gente ajudasse os colegas a se interessarem mais em ler livros. Uma tarefa bem difícil. Todo mundo só fica mexendo no celular [...]. Mas pesquisamos, estudamos e descobrimos que poderíamos fazer podcasts para colocar na internet.

ALF4: Eu compreendo que essa maneira de estudar é mais dinâmica e produtiva do que somente assistir as aulas com um professor falando. Claro que dá bastante trabalho.

ALF6: Eu gostei muito de participar desse projeto. Sempre gostei de ler, mas com essa experiência, aprendi a importância da leitura na minha vida. Pude também fazer algo realmente importante como aluna, que é fazer com que mais alunos passem a gostar de ler.

ALF7: No começo, eu não achei interessante entrar num projeto só para fazer outras pessoas gostarem de ler os livros que leio. Sempre achei que cada um deve fazer o que quer. Mas a professora estava tão animada [...]. Foi um negócio bem trabalhoso [...].

Nas assertivas dos participantes ALF3, ALF4 e ALF7, identificamos a crença de que a aprendizagem baseada em projetos exige trabalho e esforço. No entanto, enfatizam que se trata de

Interdisciplinar, Săo Cristóvăo, UFS, v. 33, jan-jun, p. 84-100, 2020 D0l: https://doi.org/10.47250/intrell.v33il.14179 
uma metodologia dinâmica e produtiva. Talvez isso esteja relacionado ao fato de que o trabalho por projetos desafia o educando a tomar decisões, buscar alternativas, estabelecerem metas e a persistirem no seu alcance, mesmo diante das dificuldades (MORAN, 2018). Também inferimos que, ao longo do processo, eles (ALF1 e ALF6) foram construindo novas crenças, tendo em vista afirmarem que a metodologia utilizada trouxe benefícios como o estímulo à pesquisa, à reflexão e à ação. Em relação a isso, Valente (2005, p. 24) nos lembra que o educador deve intervir para que o aprendiz seja capaz de transformar as informações em conhecimento através de atividades que envolvam ações reflexivas.

É possível ainda perceber, nas falas de ALF1 e ALF6, que os participantes manifestam a crença de que o projeto contribuiu para o aumento da autoconfiança: "essa experiência mostra que é possível que simples alunos como nós, do interior, possam criar uma coisa bem inovadora [...]" (ALF4); "Pude também fazer algo realmente importante como aluna". (ALF6). As crenças são moldadas, de modo geral, na interação social e referem-se aos significados que são construídos nos discursos anunciados, nas relações cotidianas. (BARCELOS, 2007). Sendo assim, entendemos que o ambiente interacional criado provocou mudanças de crenças. Todavia, as novas crenças incorporadas têm sua eficiência testada, correndo o risco de serem descartadas (PAJARES, 1992). Por isso, é importante um trabalho contínuo de estímulo aos alunos em sala de aula.

Percebemos que os informantes passaram por um percurso similar ao indicado por Moran (2018, p. 415) como sendo propício para o ensino e aprendizagem, isto é, "ensinar e aprender tornam-se fascinantes quando se convertem em processos de pesquisa constantes, de questionamento, de criação, de experimentação, de reflexão e de compartilhamento crescentes". E, considerando que "[...] a experiência, para ser educativa, deve conduzir a um mundo expansivo de matérias de estudo, constituídas por fatos ou informações, e de ideias" ${ }^{4}$. (DEWEY, 1978, p. 118), apresentamos as crenças dos participantes sobre os resultados, expectativas e aprendizagens construídas através de suas vivências no projeto desenvolvido.

4 "[...] la experiencia, para ser educativa, debe conducir a un mundo expansivo de materiales de estudio, compuesto de hechos o información e ideas" (DEWEY, 1978, p. 118). 
ALF1: [...] eu aprendi sobre várias coisas: escrever uma resenha de livro, editar áudio, usar várias ferramentas digitais, criar podcasts, criar blogs.

ALF3: [...] Mas pesquisamos, estudamos e descobrimos que poderíamos fazer podcasts para colocar numa página na internet ao lados de nossos livros preferidos (em PDF). [...] Eu aprendi a produzir blogs, podcasts. Percebi que posso criar materiais interessantes e publicá-los na internet. O resultado ficou show. Participar desse trabalho é muito gratificante. Ganhamos até prêmio, medalhas e várias homenagens na escola e na prefeitura. [...] Creio que os nossos colegas vou ver a leitura de outro jeito. Eu mesmo percebi que, por causa da leitura, podemos conquistar o mundo.

ALF4: [...] tem que pesquisar mais, tem que pensar muito sobre objetivos, maneiras de alcança-los, etc. [...] Mas no final deu tudo certo e até ganhamos o segundo lugar na última fase do Ceará Científico.

ALF6: Aprendi a usar várias coisas da internet, não somente as redes sociais, mas coisas úteis, como criar podcasts interessantes, criar páginas, aplicativos e muito mais. Hoje em dia, precisamos saber não só se comunicar através dessas tecnologias mas a usá-las para resolver ou amenizar problemas da sociedade. Espero que meus colegas gostem dos nossos podcasts e comecem logo a ler. Agradeço à professora pela paciência.

ALF7: [...] aprendemos muitas coisas sobre leitura, resenhas, podcasts e outras coisas da internet [...] estou muito feliz com o resultado. [...] Deu tudo certo e vejo agora que valeu muito a pena [...]Mas o mais legal foi ver que a equipe se uniu muito no final e eu sinto que construímos laços de amizade pra vida toda.

Os trechos relatados pelos alunos formadores revelam que as aprendizagens foram construídas na prática, ou seja, os estudantes deixaram de ser meros receptores dos conteúdos e assumiram a condição de protagonistas, envolvidos com suas próprias aprendizagens, numa causa social. No trabalho por projetos é, de fato, possível formar um estudante questionador, investigador e sensível às causas sociais (HERNÁNDEZ, 1998a). Os resultados indicam ainda que os participantes demonstram consciência de que os conhecimentos construídos só foram possíveis em consequência do processo de investigação realizado. Essa constatação está

Interdisciplinar, Săo Cristóvầ, UFS, v. 33, jan-jun, p. 84-100, 2020 D0I: https://doi.org/10.47250/intrell.v33il.14179 
evidente na passagem: "tem que pesquisar mais, tem que pensar muito sobre objetivos, maneiras de alcançá-los, etc.[...]. Mas no final deu tudo certo" (ALF4).

De forma mais específica, os formadores afirmam que desenvolveram habilidades em produção de textos (resenha) e quanto ao uso de algumas tecnologias digitais (blogs, podcasts, aplicativos). Atividades como essas trazem como consequência o letramento digital (COSCARELLI; RIBEIRO, 2014) ou os multiletramentos (ROJO, 2012). Ademais, Kenski (2012) considera que as concepções de linguagem, de escrita e de leitura são ampliadas quando as tecnologias digitais são integradas às atividades escolares.

No que concerne ao ponto de vista em relação às aprendizagens construídas, os participantes acreditam que as tecnologias digitais oferecem muitas possibilidades, além do simples uso de redes sociais, identificando, inclusive, que podem ser usadas em benefício da comunidade, como se observa em ALF6. Para Ribeiro (2016), o tempo da experiência com as tecnologias na escola é fundamental para encontrar as melhores formas ou possibilidades de uso desses recursos para o ensino. A voz dos estudantes sobre as tecnologias digitais no ensino, a partir dessa experiência, sinaliza para a possibilidade de um ensino voltado para a produção de conteúdo pelo próprio aluno, como se percebe na maioria dos relatos. Ao criarem os podcasts e o blog, eles sentiram-se capazes de produzir algo importante para si e para a comunidade, como se vê na narrativa de ALF6: "resolver ou amenizar problemas da sociedade"; ou em ALF3: "criar materiais interessantes e publicá-los na internet".

A BNCC (2017) propõe que escola deve estar atenta aos jovens, enxergando-os não apenas como consumidores, mas como protagonistas, numa sociedade de cultura digital. Assim, ao produzirem conteúdos, estão protagonizando situações de construção do conhecimento e refletindo criticamente sobre os conteúdos e produtos disponíveis.

As concepções dos estudantes sobre os resultados sugerem que o projeto foi bem-sucedido e teve repercussões significativas, como "laços de amizade", e que a conquista de um prêmio em nível estatual elevou a autoestima e a autoconfiança dos estudantes. Da mesma maneira, eles demonstraram expectativas positivas em relação à receptividade do projeto junto aos demais 
colegas, como é destacado por ALF3: "creio que os nossos colegas vão ver a leitura de outro jeito". A sala de aula, portanto, se constitui em um ambiente propício ao desenvolvimento das crenças e, refletir sobre crenças de alunos relativas a suas aprendizagens pode, consoante Barcelos (2006), influenciar suas ações e motivações e, por consequência, determinar seu sucesso ou fracasso. Identificamos, nos relatos produzidos pelos alunos formadores, algumas dificuldades surgidas durante o desenvolvimento do projeto, conforme se vê nos relatos a seguir.

ALF1: [...] Muita coisa pra fazer nas horas vagas. As vezes atrapalhava minhas atividades da escola. [...] Não gostei quando soube que somente dois alunos iriam nos representar. Achei injusto, pois nem todos participaram de tudo.

ALF4: A gente tem que se reunir sempre fora do horário normal das aulas, tem que pesquisar mais, tem que pensar muito sobre objetivos, maneiras de alcançá-los. [...] a parte complicada é que trabalhar em grupo, às vezes, sobrecarrega uns mais que outros. $\mathrm{Eu}$, por exemplo, quando disse que seria bom criar um aplicativo para facilitar o acesso ao blog, todo mundo da equipe disse que eu deveria fazer a maior parte porque sabia mais de internet.

ALF7: Foi um negócio bem trabalhoso, às vezes me estressava com alguns colegas que queriam fazer só a sua parte e não queriam ajudar os outros na hora das dificuldades. Aí a professora sempre conversava sobre colaboração, solidariedade, essas coisas [...]

Os participantes destacam que as atividades do projeto modificaram à rotina a qual estavam acostumados: "às vezes atrapalhava minhas atividades da escola" (ALF1) ou "a gente tem que se reunir sempre fora do horário normal das aulas, tem que pesquisar mais (...)" (ALF4). Fica evidente que essas foram algumas dificuldades encontradas no início das ações do projeto. Para Barcelos (2007), é fundamental observarmos o contexto de como as crenças se situam. Assim, levando em consideração que os participantes deste estudo tinham uma carga horária de 20 horas/aula semanais, parece-nos desafiador inserir mais horas de estudo e pesquisa em seus horários de descanso.

Interdisciplinar, Sằo Cristóvăo, UFS, v. 33, jan-jun, p. 84-100, 2020 D0l: https://doi.org/10.47250/intrell.v33il.14179 
Para além de uma educação voltada para a formação acadêmica dos estudantes, o que se espera, segundo a BNCC (2017), é que aconteça uma formação integral, que passa pelo reconhecimento de que o ensino deve garantir uma aprendizagem significativa para que eles atuem de forma plena na sociedade. Nesse sentido, a BNCC (2017, p. 14) entende que o estudante precisa, além de desenvolver habilidades relacionadas à comunicação, à criatividade, à criticidade, à participação e à produtividade, ser também colaborativo, resiliente e responsável. Também para Behrens (2013), os docentes precisam promover a formação humana num ambiente de pesquisa e cooperação, acrescentando que as tecnologias digitais oferecem oportunidades reais de trabalho colaborativo.

Porém, notamos que os relatos de alguns participantes revelam dificuldades relacionadas ao trabalho colaborativo. De fato, sabemos que desenvolver atividades em equipe exige resiliência para tentar resolver possíveis desentendimentos. Para ALF1, nem todos foram reconhecidos da mesma maneira. Segundo esse participante, houve injustiça em relação a quantidade de alunos que apresentaram o projeto no evento científico. Já para ALF4, houve dificuldade em relação à sobrecarga de alguns participantes, em determinados momentos. $O$ trabalho colaborativo requer diferentes estratégias para superar as dificuldades. O diálogo é, para Freire (2005), a essência da educação. Assim, o professor deve sempre conduzir os trabalhos, buscando dialogar e encontrar alternativas para que todos possam colaborar com equidade. Na fala de ALF7 ("aí a professora sempre conversava sobre colaboração, solidariedade, essas coisas"), é possível identificar que houve esforço por parte da professora para superar possíveis conflitos por meio do diálogo. Para Miccoli (2014), é necessário haver mais atenção e investigações sobre a relação professor-aluno para que o processo de ensino e aprendizagem possa ser repensado e, talvez, reformulado.

\section{Consideraçồes finais}

Neste artigo analisamos os relatos de experiência produzidos pelos alunos envolvidos na primeira fase do projeto "Leitores que forma leitores". A partir do referencial teórico, compreendemos que incentivar a leitura tem a ver com o universo que se cria e com a dialogicidade que entrelaça os membros desse universo. 
(FREIRE, 2005). Ademais, na contemporaneidade, nossos alunos, interagindo de forma cada vez mais efetiva com as tecnologias, podem e devem ter acesso à leitura em outros suportes e de outras maneiras. (ROJO, 2012). Compreendemos também que o estudante, ao protagonizar sua aprendizagem, tem mais chances de êxito. (HERNÁNDEZ, 1998a). E, quando se alia a isso as teologias digitais, os alunos se sentem mais motivados. (MORAN, 2018). Por fim, entendemos que refletir sobre as experiências e crenças que envolvem professores, alunos, ensino e aprendizagem é primordial para transformações positivas no âmbito educacional. (BARCELOS, 2006; MICCOLI, 2014).

Os resultados apontam para a construção de crenças relacionadas ao processo metodológico adotado, às aprendizagens construídas, aos resultados e/ou expectativas e às dificuldades encontradas. Sobre o processo metodológico, identificamos a crença de que a aprendizagem baseada em projetos exige trabaIho e esforço, porém, acreditam ser uma metodologia dinâmica e produtiva e que contribuiu para o aumento da autoconfiança.

Sobre as aprendizagens construídas, os participantes revelam que assumiram a condição de protagonistas envolvidos com suas próprias aprendizagens e que desenvolveram habilidades em produção de textos (resenha) e no uso de algumas tecnologias digitais (blogs, podcasts e aplicativos). Os resultados atestam que essas experiências multimodais estimularam a colaboração, a autoria de conteúdo e o espírito investigativo. Ao se colocaram no centro do processo com o uso das tecnologias digitais, fez-se emergir um ensino híbrido, com ênfase nos multiletramentos. Em relação aos resultados, manifestam a crença de que houve resultados significativos como "laços de amizade" e conquista de prêmio e homenagens. Demonstraram ainda expectativas positivas em relação à receptividade do projeto junto aos demais alunos e sobre a mudança de postura em relação ao ato de ler. No que concerne às dificuldades, os participantes reclamaram da mudança de rotina e de problemas relacionados ao trabalho em grupo (sobrecarga de trabalho de alguns participantes em determinados momentos e reconhecimento desigual em relação à participação em um evento científico). Compreendemos, a partir dessas reflexões, que o estudo das experiências das crenças e pode ser um forte auxílio para uma educação de qualidade. 


\section{Referências}

ALMEIDA, E. B; VALENTE, J. A. Integração currículo e tecnologias e a produção de narrativas digitais. Currículo sem fronteiras, v. 12, p. 57-82, 2012.

BARCELOS, A. M. F. Crenças sobre aprendizagem de línguas, Linguística Aplicada e ensino de línguas. Linguagem e Ensino, Pelotas, v. 7, p.123-156, 2004.

BARCELOS, A. M. F. (Orgs.). Crenças e ensino de línguas: foco no professor, no aluno e na formação de professores. Campinas: Pontes Editores, 2006.

BARCELOS, A. M. F. Reflexões acerca da mudança de crenças sobre ensino e aprendizagem de línguas. Revista Brasileira de Linguística Aplicada, Minas Gerais, v. 7, p. 109-138, 2007.

BEHRENS, M. A. Projetos de aprendizagem colaborativa num paradigma emergente. In: MORAN, J. M.; BEHRENS, M. A.; MASSETO, M. T. Novas tecnologias e mediação pedagógica. 21 ed. Campinas: Papirus, 2013. p. 67-132.

BRASIL. Ministério da Educação. Secretaria da Educação Básica. Base nacional comum curricular. Brasília, DF, 2017. Disponível em: <http://basenacionalcomum.mec.gov.br/wp-content/uploads/2018/02/bncc-20dez-site.pdf>. Acesso em: 10 jan. 2019.

COSCARELLI, C. V.; RIBEIRO, A. E. Letramento Digital. In: FRADE, I. C. A. S.; VAL, M. G. C.; BREGUNCI, M. G. C. (Orgs.). Termos de Alfabetização, Leitura e Escrita para Educadores. Belo Horizonte: CEALE/UFMG, 2014.

DEWEY, J. Vida e educação. Trad. estudo preliminar por Anísio S. Teixeira. São Paulo: Melhoramentos; Rio de Janeiro: Fundação Nacional de Material Escolar, 1978.

DEWEY, J. Experiência e Educação. 3 ed. São Paulo: Cia. Editora Nacional, 1979.

FREIRE, P. Pedagogia da autonomia: saberes necessários à prática educativa. 42 ed. São Paulo: Paz e Terra, 2005.

FREIRE, P. A importância do ato de ler: em três artigos que se completam. São Paulo: Cortez, 2011.

GOULART, C. Letramento e Novas Tecnologias: questões para a prática pedagógica. In: COSCARELLI, C. V.; RIBEIRO, A. E. (Orgs.) Letramento Digital: aspectos sociais e possibilidades pedagógicas. Belo Horizonte: Autêntica, 2007.

HERNÁNDEZ, F. Transgressão e mudança na educação: os projetos de trabalho. Trad. Jussara Haubert Rodrigues. Porto Alegre: Artmed, 1998a.

HERNÁNDEZ, F. Repensar a função da escola a partir dos projetos de trabalho. Pátio, São Paulo, n. 6, p. 27-31, 1998b.

Interdisciplinar, Sầo Cristóvầo, UFS, v. 33, jan-jun, p. 84-100, 2020 D0I: https://doi.org/10.47250/intrell.v33i1.14179 
KENSKI, V. M. Tecnologias e ensino presencial e à distância. 9 ed. Campinas: Papirus, 2012.

MICCOLI, L. Por um tratamento da experiência na linguística aplicada ao ensino de línguas estrangeiras. Revista do Programa de Estudos Linguísticos e Literários em Inglês, São Paulo, v. 12, p. 263-283, 2007.

MICCOLI, L. Pesquisa experiencial em contextos de aprendizagem: uma abordagem em evolução. Campinas, SP: Pontes Editores, 2014.

MORAN, J. M. Ensino e aprendizagem inovadores com tecnologias audiovisuais e telemáticas. In: MORAN, J. M.; BEHRENS, M. A.; MASETTO, M. T. Novas tecnologias e mediação pedagógica. 21 ed. Campinas: Papirus, 2013, p. 11-65.

MORAN, J. M. Metodologias ativas para uma aprendizagem mais profunda. In: BA$\mathrm{CICH}, \mathrm{L}$.; MORAN, J. (Orgs.). Metodologias ativas para uma educação inovadora: uma abordagem teórico-prática [recurso eletrônico]. Porto Alegre: Penso, 2018.

OLIVEIRA, M. N.; LIMA, E. A. Crenças de alunos sobre a leitura de textos multimodais. Diálogo das Letras, v. 05, p. 110-124, 2016.

PAJARES, M. M. Teachers' beliefs and educational research: cleaning up a messy construct. Review of educational research. v. 62, p. 307-332, 1992.

RIBEIRO, A. E. Tecnologia digital e ensino: breve histórico e seis elementos para a ação. Linguagem e Ensino, Pelotas, v. 19, p. 91-111, 2016.

ROJO, R. Pedagogia dos Multiletramentos. In: ROJO, R.; MOURA, E. (Orgs.). Multiletramentos na escola. São Paulo: Parábola Editorial, 2012. p. 11-32.

SOARES, M. Alfabetização e Letramento: Caminhos e descaminhos. Pátio, Porto Alegre, n. 29, p. 18-22, 2004.

VALENTE, J. A. Pesquisa, comunicação e aprendizagem com o computador. O papel do computador no processo ensino-aprendizagem. In: ALMEIDA, M. E. B.; MORAN, J. M. (Orgs.). Integração das tecnologias na educação. Brasília: Ministério da Educação/SEED/TV Escola/Salto para o Futuro, 2005, p. 12-17. Disponível em: <http://www.tvebrasil.com.br/salto>. Acesso em: 5 mai. 2019.

ZACHARIAS, V. R. C. Letramento digital: desafios e possibilidades para o ensino. In: COSCARELLI, C. V. Tecnologias para aprender. São Paulo: Parábola Editorial, 2016. p. 15-26.

ZILBERMAN, R. Porque a leitura da literatura na escola. In: AMORIM, M. A.; CARVALHO, A. M.; GERHARDT, A. F. L. M. (Orgs.) Linguística aplicada e ensino: língua e literatura. Campinas: Pontes, 2013. p. 209-230.

Interdisciplinar, Sằo Cristóvăo, UFS, v. 33, jan-jun, p. 84-100, 2020 D0I: https://doi.org/10.47250/intrell.v33i1.14179 